\title{
Challenges in Agribusiness and Rural Tourism Development in Albania
}

\author{
Prof. Asoc. Dr. Bajram Korsita \\ University of Aleksander Moisiu, Faculty of Business, Department of Management, Durres, Albania \\ Email: bajramkorsita@yahoo.com \\ Dr. Luftim Cania \\ University of Aleksander Moisiu, Faculty of Business, Department of Management, Durres, Albania \\ Email: luftimcania@yahoo.com
}

\section{Doi:10.5901/ajis.2016.v5n3s1p105}

\begin{abstract}
Agricultural sector is one of sectors that has a huge impact on the economy. Agricultural production is increasing but it has not had any lasting impact. On the other hand, the impact of investment in value chains, including different factors, resulted successful in increasing agricultural productivity and profitability, and this impact have demonstrated a high degree of economic stability. Thus, tourism is one of the most perspective sectors in Albania. There are also many difficulties, such as the lack of services, marketing or infrastructure. Furthermore, agribusiness sector and rural tourism have difficulties in funding because of lack of technology, lower product quality standards and market. Based on these facts, in this paper, we have analysed empirically difficulties of this sector and the opportunity to develop it. The main purpose of our research is to design a strategy for development of agribusiness and rural tourism sector. The methodology is based on primary and secondary sources. More specifically, we refer to previous research by other authors and other studies made by government and private agencies. The main goal is to provide data through interviews of business representatives.
\end{abstract}

Keywords: agribusiness, rural tourism, value chains, agriculture productivity

\section{Introduction}

Tourism is a catchword for rural development, engagement in projects to alleviate poverty and the preservation of cultural diversity of the indigenous community (Doohyun et al., 2014). In recent years there have been changes in the Albanian Agribusiness Sector. These have had a positive impact on this sector, but its development is still low. Some of the numerous barriers are: production, marketing, information and lack of access to appropriate financial products. Actually the demand for rural goods and tourist services in this direction is high intensity, while the ability of businesses operating in these areas to fulfill this demand remains at a low level. A lot of the products are sold in the market due to lack of conservation and their packaging. On the other hand, tourism services have low quality, low cost, low margins and poor customers.

The agricultural sector in Europe is facing dramatic changes due to various factors, such as climatic changes, changes in the policy environment and development of tourism. (Straaten, 2000). The nature of the process of land reform carried out during the 1990s has contributed to the chronic structural nature of rural poverty. Although most people received land from this process, land distribution was far from ideal. Most people received only very small areas, usually broken in to several parcels. Thus the production base for poor farmers is impractical, and many have leased or sold their entitlements, or else have chosen to allow it to remain fallow. Small-scale producers continue to have great difficulty in producing marketable surpluses of produce at a profit. While they produce a wide range of commodities, their access to the factors of production (machinery, credit, inputs) remains sub-optimal and their access to information is poorly addressed through the publicly available extension services. They typically sell marketable produce immediately after harvest at a significant price disadvantage. Poor people in rural areas of Albania find great difficulty in engaging in entrepreneurial activity. They are constrained in this by a number of inter-related factors. These include: lack of access to formal lines of finance, inadequate education, lack of access to land, lack of appropriate financial products for poor people, small of scale of operations and lack of technical and market knowledge. The combined impact of these factors is that entrepreneurial activity by poor people remains subdued in rural areas. The attempt to combine agricultural and tourism services, which are known as agro-tourism, is an important approach for rural development (Tanupol et al., 2000). Thus, our research objectives are: (a) to identify and appreciate the problems of the rural tourism; (b) to consider 
how this sector can be developed ; and (c) to provide valuable strategies for the development of this sector.

\section{Methodology}

The main purpose of our research is to design a strategy for development of agribusiness and rural tourism sector. This paper is mainly based on the study and review of several papers by national and international authors. As secondary sources were used earlier studies by different authors, periodic reports from government agencies and consulting corporation. Meanwhile primary data was collected through interviews with business representatives. To assess the problems and to develop the strategies for rural tourism, we conducted a desk research and held direct meetings with representatives of selected business. Also, we conducted the farmers for interviews. After that, we used qualitative analysis for generating results from findings.

\section{Limitations on Sector Growth}

Rural tourism is stable for supporting socio-economic problems in rural areas and it is also an important source of living for the rural population (Tchetchik, Fleischer, \& Fleischer, 2008). However, there are some limitations. The limitations of this sector are numerous and they affect each other. The reduction or elimination of these restrictions will be an opportunity of developing this sector. Some of the limitations are: infrastructure, finance, markets, technological.

Infrastructure: Rural infrastructure remains in poor condition or non-existent in the more remote parts of Albania. While some of the main roads and facilities are in fair condition, it is the condition of rural access roads, energy supplies and water supplies for both domestic and irrigation needs which have the greatest negative impact on limiting agriculturalbased income growth. There are also severe constraints on communications in many localities.

Finance. The relative lack of provision of appropriate financial products and tools for agricultural-based rural enterprises in mountain areas remains a serious constraint on the growth of incomes from these sources. While there has been a general improvement in the provision of medium and longer-term finance for enterprises. The supply remains concentrated in more easily accessible areas, and is almost non-existent in some areas. In addition, there are several other important factors that limit the availability of rural finance. In summary, these are: lack of viable Banks and Microfinance institutions in many areas, under-valuation of rural assets with the potential to be used for collateral, lack of assets to be used for collateral by the youth and by potential female entrepreneurs and lack of facilities to enable viable SMEs to gain access to long-term venture capital or equity financing.

Markets: The market demand for Albanian agricultural commodities and rural-based products remains strong. In the first place, there are significant imports or agricultural commodities which can be grown locally, even of items grown in the programme area (e.g. chestnuts, herbal teas). The proximity to Europe, and the new initiatives for easier trading systems, also provide new opportunities for exports to the EU. However, there are serious constraints which continue to operate on the supply side of the marketing process, with resultant limitations on the ability of rural SMEs to provide avenues for sustainable income growth. The most important of these are: (a) lack of investment in production, processing, storage and transport facilities. There has been very limited investment from private sources in the sector, with the limited investment mainly being provided through official development assistance channels; (b) lack of access to short-term and seasonal finance for production. Trade in commodities, including those for exports, takes place in an informal and un-managed setting. Vendors and purchasers have to use personal knowledge and contacts in order to make trades. The result is that prices achieved are sub-optimal, substantial amounts of produce goes un-harvested (specifically in the case of chestnuts, pomegranate and medicinal herbs occurring naturally in forest areas), unsold and is wasted while at the same time there is un-met demand. At the farm level, there has been very little development of contract farming or supply procedures. Those that do exist are not suitable for large-scale replication because they are based on personal knowledge and social pressure rather than on systematic and business like principles. Marketing of tourism products is done in an amateurish and un-coordinated way, to the detriment of the buyers of the product as well as the purveyors. There is no system of booking, and few ways of determining the nature of services being offered. There are few links between accommodation services and others, such as activities and restaurants. Moreover, the overall quality of the services offered is poor, despite the undoubted beauty of many localities. Further, the lack of proper waste disposal systems means that the environment is substantially degraded by an abundance of litter and household rubbish.

Technological: With the inadequate levels of investment in the past decade, most Albanian agriculture and agribusiness continues to use out-dated and inadequate technology, especially in the mountain areas. Much of the agricultural equipment in use dates from the era of the centrally planned economy, and is thus both inefficient and costly 
to operate. There is also lack of application of modern standards of hygiene, quality, reliability and grading. All of these make it more difficult for enterprises to successfully enter export markets, especially those in the EU, as well as raising costs at the farm and enterprise levels.

\section{Strategic Approach to Develop the Agribusiness}

Rural tourism is a convergence of rural and tourism development. Moreover, rural sustainable livelihoods is a convergence of rural development and sustainable development (Shen, Hughey dhe Simmons 2008). The impact from investment in value chains involving a broad rangers of actors has proved successful in raising agricultural productivity and profitability and has also demonstrated a higher degree of sustainability. Rural tourism is marginalized some extent in substitution for rural development and its pursuit will depend on agricultural activity and community involvement (Hall, Kirkpatrick and Morag, 2005). Agribusiness must to accelerating the shift to a private sector led structural transformation, increasing opportunities for the poorest by enabling them to exploit non-agricultural opportunities and prioritising districts with higher than average poverty rates.

- The demand for medium and long term rural finance is largely unsatisfied, despite the efforts of several development initiatives;

- The impact of the rural finance which has been provided has largely been positive in terms of employment and income creation, enterprise development and improvements in export performance;

- So far, despite intentions to the contrary, the application of a Value Chain Approach to rural investment has only occurred in a piece-meal fashion;

- There is a large unsatisfied demand for many rural products;

- There is still a large population of under-employed rural people in need of permanent and remunerative employment.

In order for companies to be able to compete, there should be an efficient market system. It is often argued that the development of sustainable rural tourism cannot be achieved without the full support of rural community (Doohyun et al., 2014). However, market efficiency is not a normal situation for many sub-sectors of the agricultural industry in Albania. Its consequences are caused losses, sub-optimal prices, supply shortages and irregularities and loss due to competition. A tourist offer is very fragmented (Hall, Mitchell and Roberts, 2005). Inefficiencies are prominent in the relationships between small farmers and processors/markets, between suppliers and local markets and also between various producers and export markets. Although there have been some efforts to remove such inefficiencies, they remain a serious impediment. Similarly, enterprises need to use technology that is sufficiently modern and efficient to enable them to compete on the basis of cost and quality. Actually, social-cultural heritage maintenance is also considered an essential component of sustainable development the natural resources and socio-cultural heritage maintenance (Holloway and Taylor, 2006). Again, these are not features of the majority of agricultural enterprises, contributing to their difficulty in competing and making sustainable profits. The approach to technological improvements is in two directions. Firstly, in the case of financial development, technological innovations would be developed in concert with the development and application of financial services. Secondly, in the case of individual enterprises supported, the application of appropriate new technology would be embedded within the investment. There would also be requirements for all agro-processing investments to be compliant with best practice environmental standards, particularly those such as dairy processors which provide perishable food products directly to the public. Such environmental standards would also be applied to producers to avoid the possibility of unintended environmental costs being passed on to the associated community or public sphere. Sustainable tourism model is intended to reconcile the tensions between the partners, social, environmental and economic factors and keeping the balance in the long term (Lane, 2005). The scenario in the mountainous rural Albania is one of the small plots of land and fragmented land for many of those who have some, and many rural people being ill-qualified for agricultural entrepreneurship. Moreover, even amongst people do own and farm the land, there are many who are ill-suited to farming due to their own skill base, age or gender. It follows that the most attractive means for genuine poverty alleviation is for rural employment creation. Efforts by agricultural SMEs to develop contract farming have been observed in some localities. However, as noted, these are based on personal knowledge and are thus inherently limited in size, outreach and scope of activities. Procedures for engagement between a company/market entity and farmers in a contract farming system need to be based on principles of transparency, trust and effective enforcement, together with in-built financing.

Transparency. The company would need to ensure that all of the information pertaining to financial and technical dealings with farmers would be transparently available. The policy on company mark-ups and pricing for services and 
inputs would be negotiated and agreed prior to any agreement. The costs would be overtly disclosed by the company to relevant community organisations of farmers participating in a scheme, and directly to the farmers themselves. This process would be maintained through an "open book system" whereby the company would specifically enable farmers to have full knowledge of the derivation of prices and charges pertaining to farmer's transactions.

Trust. Various other devices would be used to engender trust between the parties. Firstly, a contract would be negotiated between the each company and participating farmers, with farmers organisations providing negotiation on behalf of their members. This would be varied from time to time to suit circumstances, but only with the full knowledge and participation of the farmers and their organisations. Secondly, an Independent Audit of procedures would be carried out periodically by a competent and reputable organisation. This would be done annually at the commencement of the agreement, but could be done less frequently once trust is evidently established. This would be used to provide a guarantee that stated procedures and calculations were accurate, and that the procedures themselves were robust and fair to all parties. Thirdly, the system would use the authority of the farmer's organisations and their leaders to ensure appropriate communication and discipline. Fourthly, companies would endeavour to use trusted and well-educated local people within its system of engagement with farmers and provision of services to them.

Enforcement. There would need to be agreed methods of enforcement to avoid delinquent behaviour by either party. For the most part, enforcement of farmer behaviour would be through a form of group responsibility, managed by farmer's organisations. While there would be a legally binding agreement between the parties, resorting to the formal legal system for redress would be too slow and inconvenient, as matters would require rapid resolution so as not to disrupt agricultural operations. For example, the farmers organisation for each participating group of farmers would be responsible for ensuring compliance within their group for technical matters such as timely and assured crop delivery and crop quality management. Failure of one or more of the group to undertake agreed actions would need to be covered by the group as a whole. Similarly, the farmer's organisation would be responsible for the financial compliance of farmers under its control, and would be obliged to make good any shortfalls. The behaviour of each company would also need to be governed by the possibility of sanctions. If a farmer or farmer's organisation believed that a company had not discharged its obligations, they would be able to seek redress through direct engagement with the company. If intermediation at this level did not succeed, then the matter could be referred to an independent arbitrator (honest broker). The arbitrator would need to be a competent yet "disinterested" organisation such as a legal arbitration practice or a reputable NGO. The identity of the arbitrator would need to be agreed jointly between each company and the participating farmers organisations, and its decisions would be binding on both parties. The arbitrator would be able to invoke sanctions on a company if a case against it were proven. The severity of the sanctions would be pre-determined by negotiation between the parties.

Financing. The system would have in-built financing, usually from a bank or MFI, within a "Tri-Partite Agreement". Such a system would operate as follows: (a) the Farmers and the Processor would negotiate a contract, which would include specification of improved procedures requiring specific inputs, as well as pricing and standards parameters; (b) the Farmers and the Processor would jointly approach a bank with which they already have a relationship, seeking partial or complete financing for the required inputs; (c) they bank would become a party to the agreement, with its role being to provide the agreed finance in a timely way to the farmers, and to manage repayments. The Processor would pay the Farmers only through their account with the bank and it would deduct repayments from this on an agreed schedule; (d) while the bank may require some collateral or guarantee initially, it is expected that it would ease this requirement after it becomes confident of the robustness of the system.

\section{Conclusions}

Through this empirical research, we have found difficulties and opportunities for development of this sector. Some of the limitations are: infrastructure, finance, markets, technological. However, rural tourism has the potential to be developed. The coordination between farmers and market will lead to the development of rural tourism. Some strategies may focus on transparency, trust, effective enforcement and financing. Another way is to invest in technology. Why? Technology will help financial services and thus individual enterprises will be supported by applying new technology appropriate for their investments.

\section{References}

Brscic, K. (2006). The impact of agrotourism on agricultural production. Journal of Central European Agriculture Vol 7, № 3.

Doohyun, H., Stewart William P. \& Dong-wan Ko. (2014). Community Behavior and Sustainable Rural Tourism Development. Journal of 
travel Research. May 2012 vol. 51 no. 3.

Gilbert, D. (1989). Rural Tourism and Marketing: Synthesis and New Ways of Working. Tourism Management, 39-50.

Halfacree, K. 1993. Locality and social representation: apace, discourse and alternative definitions of the rural. Journal of Rural Studies, 9 (1): 23-37.

Hall, D., Kirkpatrick, I. \& Morag, M. (2005). Rural Tourism and Sustainable Business. UK: Channel view publications.

Hall D., Mitchell, M. and Roberts, L. (2005). Tourism and the Countryside: Dynamic Relationship, in Hall D., Roberts, L. and Mitchell, M. (Ed.) New Directions in Rural Tourism, Ashgate, Aldershot, 3-18.

Holloway, J., C. and Taylor, N. (2006). The Business of Tourism, Seventh edition, Prentice Hall, Harlow.

Roberts, L. \& Hall, D. (2004). "Consuming the countryside: Marketing for "rural tourism"." Journal of Vacation Marketing (Sage publications) 10 , no. 3, pp 253-263

Straaten, J. (2000). Can Sustainable Tourism Positively Influence Rural Regions?, in D. Hall and G. Richards (Ed.), Tourism and Sustainable Community Development, Routledge, London, 221- 232.

Tanupol, N., Penkan, D., Tanupol, S., Jarungkon, C., Punoi, T. and Supaluck, M. .2000 Development of ecotourism business in Bangpong community, Maejo University, Thailand.

Tchetchik, A., Fleischer, A. \& Fleischer, I. (2008) :"Differentiation and Synergies in Rural Tourism: Estimation and Simulation of the Israeli Market." American Journal of Agricultural Economics Vol. 90., no. No. 2, 553-570. 